noxythiolin-free control. A 10- $\mu$ l sample from each tube was plated on blood agar at $0, \frac{1}{2}, 1,2,4$, and $24 \mathrm{~h}$. The results for one of the organisms tested with $10^{6}$ bacteria added to $1 \mathrm{ml}$ of solution are shown in the table. It can be seen that $2 \mathrm{~h}$ exposure was required for killing by a $10 \mathrm{~g} /$ solution of noxythiolin, although the MBC as previously determined was $2 \mathrm{gl}$. Two other organism (MBC $1 \mathrm{~g} \mathrm{l}$ ) when tested with $10^{5}$ organisms $\mathrm{m}$ showed complete killing by $20 \mathrm{~g} / \mathrm{in} 1 \mathrm{~h}$, by $10 \mathrm{~g}$ in $2 \mathrm{~h}$ and by both $5 \mathrm{~g} /$ and $2.5 \mathrm{~g} / \mathrm{in} 4 \mathrm{~h}$.

Presence of persisting Bacteroides fragilis after exposure to noxythiolin

\begin{tabular}{|c|c|c|c|c|c|c|}
\hline \multirow{2}{*}{$\begin{array}{l}\text { Time of } \\
\text { exposure } \\
\text { (hours) }\end{array}$} & \multicolumn{6}{|c|}{ Noxythiolin concentration $(\mathrm{g} l)$} \\
\hline & 20 & 10 & 5 & $2 \cdot 5$ & 1.25 & 0 \\
\hline $\begin{array}{r}0 \\
1 \\
1 \\
2 \\
4 \\
24\end{array}$ & $\begin{array}{l}+++ \\
+++ \\
++ \\
- \\
- \\
-\end{array}$ & $\begin{array}{c}+++ \\
+++ \\
+-+ \\
- \\
- \\
-\end{array}$ & $\begin{array}{r}+++ \\
+ \\
++1 \\
++ \\
-\end{array}$ & $\begin{array}{r}++t \\
+++ \\
+++ \\
+++ \\
++ \\
-\end{array}$ & $\begin{array}{r}++t \\
++t \\
+\cdots+ \\
+-t \\
+++\end{array}$ & $\begin{array}{l}-++ \\
++t \\
++t \\
+++ \\
+++ \\
+\end{array}$ \\
\hline
\end{tabular}

The results of our own studies on $B$ fragilis and those of Dr Chattopadhyay on $P_{s}$ aeruginosa lead us to believe that the disc sensitivity test or determination of MIC or $\mathrm{MBC}$ as routinely applied to the study of antibiotics may be of limited value. We feel that assessment of the rate of killing is the only method likely to give a meaningful result for topical agents which may otherwise be instilled for too short a period of time, with long periods of time between treatments during which regrowth could occur. We doubt, however, whether laboratories could devote the time needed to assess the rate of killing in every case.

R H GEORGe D E Healing

Department of Microbiology,

Birmingham Children's Hospital,

' Haler, D, and Aebi, A, Nature, 1961, 190, 734

\section{Drinking behaviour}

SIR,-Your leading article entitled "Drinking behaviour" (8 October, p 914) is rather misleading in its emphasis. Alcohol is rarely a main cause of the conditions attributed to its abuse ${ }^{13}$; only a tiny minority of British drinkers (perhaps $0 \cdot 05-0 \cdot 1^{\circ}$ ) develop serious complications. Where there is an association with cirrhosis, marital strife, dementia, worktime lost, etc, the alcohol ingestion may well be a correlate or even a consequence rather than a cause.

Mental, physical, and social illnesses cause alcoholism rather than the other way round. Thus even when alcoholics abstain totally they tend to be overtly disturbed. ${ }^{4}$ If nuclear alcohol dependency is usually a symptomatic phenomenon the crucial lesson is that we must search exhaustively for underlying, often treatable, pathology. If alcoholism is diseasebased the present expensive educational drive by David Ennals in the north-east to reduce the Geordies' intake is doomed to failure.

Excessive drinkers might wreak even more havoc on themselves or society without the refuge of the bottle" " which serves as a "sinister but effective" peacemaker. This pain-relieving model suggests a more heuristic, treatment-oriented typology than the rather ineffective WHO restatement of Jellinek's excellent descriptive classification:

(Ia) Those "normals" whose life problems, leading to excessive intake, may be soluble by non-organic approach-for example, family counselling. This type, often a middle-class minority, has traditionally and, I feel, most unfortunately been confused with the following categories.

(Ib) Those "normals" for whom sociopsychological measures alone are insufficient and who therefore need pharmacological help while their underlying stress continues. A relevant analogy is the snioker who starts smoking much more when subjected to stress. Both may continue to indulge out of habit when the stress is removed, but not to excess any more. This group can return to "social" drinking, as an increasing number of studies is now showing."

(II) The "core" alcoholics needing long-term drug help in their effort at tension-discharge. They typically suffer from chronic physical and or psychiatric illness. Female alcoholics are overrepresented here in that they tend to be more psychologically disturbed."

Oral medication is usually unsuitable for maintenance treatment. ${ }^{9}$ The obvious answer is the depot phenothiazine, ${ }^{111}$ which is not only our most effective anti-aggressive agent but may even block a possible toxic-addictive complex of dopamine with a tetrahydroisoquinoline derivative of ethanol.

If this tension-reduction approach should prove scientifically fruitful we will have achieved a breakthrough in the exorcism of a very nasty "demon." The bell may toll only for those not given the chance of treatment with a depot neuroleptic.

H G KINNEL

Northgate Hospital,

Morpeth, Northumberland

Benjamin, I S, Imrie, C $\mathrm{W}$, and Blumgart, $\mathrm{L} \mathrm{H}$, in Alcoholism: New Knowledge and New Responses, ed $G$ lidwards and $M$ Grant, p 198. London, Croom Helm, 1977

orld Health Statistics Annual, 1973-1976. Genevi

ialambos, J T, in Progress in Liver Diseases, ed
$\mathrm{H}$ Popner and F Schaffner, vol 4, 567 . New York, Gopper and F Schaffiner

Gerard, I) L, Saenger, G, and Wile, R, Archives of General Psychiatry, 1962, 6, 83.

Sunday Express, 18 September 1977, p 21.

Proudfoot, A I, and Park, J, in Alcoholism: New Knowledge and New Responses, ed (; Edwards an M Grant, p 224. London, Croom Helm, 1977. Litman, G K, Once an Alcoholic, Always an Alcoholic A Revlew and Crttique Addiction Research
paper. London, Institute of Psychiatry, 1977. Beckman, L. J, Quarterly fournal of Studies on Alcohol, 1975, 36, 797

Proudfoot, A I , and Park, J, in Alcoholism: New
Knowledge and New Responses, ed $\mathrm{F}$ Edwards and M Grant, p 222. London, Croom Helm, 1977 Kinnell, $\mathrm{HG}$, ancet, $1977,2,659$. Bartholomew, A A, Quarterly Fournal of Studies on

\section{Cimetidine and gastric ulcer healing}

SIR,-Dr R J Machell and his colleagues suggest (15 October, p 1023) that the great effect of cimetidine found in our double-blind gastric ulcer trial (24 September, p 795) may partly have been due to unsuccessful randomisation, especially because the healing rate in the placebo group was very low. We should of course have been happier if the retrospective stratification had not shown that the treatment group and the control group were, by chance, not comparable in all respects, but as discussed in the paper this fact probably does not bias the results in favour of cimetidine. Also properly conducted randomised therapeutic trials are subject to stochastic variation, but it is worth pointing out that our findings are in very good agreement with those of the only previously published complete trial.

It is necessary that we learn the truth about the effect of cimetidine in a disease which is as common as gastric ulcer disease, but the full truth will emerge only when more trials have been published. Dr Machell and his colleagues mention that their trial is not complete and that a significant effect of cimetidine "has yet to emerge." This statement worries us because usually it is assumed that the results of a randomised trial are not known until the completion of the study. Otherwise it may be difficult to decide when to stop the trial.

We agree very much with Mr R S Arnot (15 October, p 1022), who states that treatment with cimetidine may lead to an increased incidence of missed gastric carcinomas if the patients are not examined sufficiently early.

K Gotlieb Jensen S RUNE

H R WuLFF

Ribe County Hospital,

Glostrup University Hospital

Herlev University Hospital, Multicentre Trial (France), in Cimetidine, ed w R
Burland and $M$ Alison Simkins, p 287. Amsterdam and Oxford, Excerpta Medica, 1977.

\section{Depression in men and women}

SIR,-Your recent leading article on this subject (1 October, p 849) very rightly focused attention on the significantly higher incidence of depression in women during their reproductive years as compared with men of comparable age and also older women. The two articles which are discussed in detail ${ }^{12}$ make some mention of the possible reasons for this, but come to no very firm conclusions on the relative importance of endocrine and other factors.

We should like to support the view that depression occurring in a cyclical manner during the premenstrual days has an endocrine component in many cases, and to advance the hypothesis that subtle neuroendocrine imbalance may well exist in the cases in which it is at present not possible to detect endocrine abnormality. Recent work from this department on patients with the premenstrual syndrome (PMS) has demonstrated a deficiency of plasma progesterone during the luteal phase in $40 \%$ of the patients investigated $^{34}$ and preliminary studies suggest a tendency to increased prolactin levels when progesterone levels are significantly decreased. ${ }^{5}$ Serum oestradiol levels may also be slightly increased in the late luteal phase." These findings are in general agreement with those of Carstensen in Uppsala. ${ }^{7} \times$ A tendency to increased prolactin levels in PMS has also been reported by others. ${ }^{910}$

It is encouraging that several recent approaches to the treatment of PMS have given beneficial results which are clearly well above the maximum $(30 \%)$ placebo effect likely to be encountered. These various approaches have recently been discussed ${ }^{11}$ and their rationale in PMS considered. They include the use of dydrogesterone, especially in patients with a luteal deficiency of progesterone, ${ }^{12}$ and high-dose pyridoxine therapy. ${ }^{13}$ Both these treatments may give complete or partial relief of symptoms in about $75 \%$ of selected cases. Research currently in progress suggests that further improvement in relief of symptoms can be obtained by individualising dose regimens and sometimes by combining dydrogesterone and pyridoxine therapy. A single-blind trial on the use of dydrogesterone in PMS is now almost completed and a similar trial using pyridoxine is about to start.

We therefore feel that there are grounds for 